\title{
IMAGENS LITERAIS DEMAIS Pensando elementos estéticos no fazer político do bolsonarismo e suas consequências

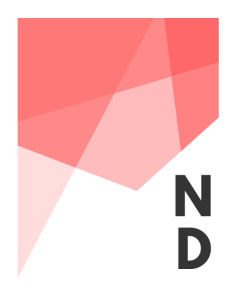

\author{
TOO LITERAL IMAGES \\ On aesthetics elements within politics making \\ of bolsonarism and its consequences
}

Jorge Scola

Universidade Federal do Rio Grande do Sul

Programa de Pós-Graduação em Antropologia Social | Porto Alegre, Brasil jhsgomes@gmail.com | ORCID iD: 0000-0001-6502-0326

\begin{abstract}
Resumo
O texto focaliza o entrelaçamento entre elementos estéticos, modos de pertencimento e a construção de grupos políticos bolsonaristas. São vistas nas cenas públicas de apoio ao mandato de Jair Bolsonaro materialidades, mensagens e imagens que relacionam religiões, Estados-Nação e sentidos de maioria cujo arranjo não deve ser compreendido como um acúmulo de referências desordenadas, mas como o acionamento de elementos que funcionam segundo uma lógica própria, a do bolsonarismo. $O$ argumento do texto é o de que a ocupação de espaços públicos por apoiadores deste governo e as formas de aparição de seus elementos estéticos mais recorrentes oferecem boas chaves interpretativas para abordagens antropológicas ao tema do bolsonarismo e do fortalecimento do conservadorismo na política contemporânea.
\end{abstract}

\section{Palavras-chave}

Antropologia da política; bolsonarismo; conservadorismo; estética e política, pertencimento político.

\begin{abstract}
This paper focuses on the entangling of aesthetics elements, modes of belonging and the construction of Bolsonarist political groups. Materialities, messages, and images that relate religions, nationstates, and senses of majority are observed in the public scenes of support for the mandate of Jair Bolsonaro. This arrangement should not be understood as an accumulation of disordered references, but as the activation of elements that works in its own logic, which is that of Bolsonarism. The argument here is that the occupation of public spaces by supporters of this government and the forms of appearance of its most recurrent aesthetic elements provide productive interpretive keys for anthropological approaches to the issue of Bolsonarism and the strengthening of conservatism in contemporary politics.
\end{abstract}

Keywords

Political Anthropology; Bolsonarism; conservatism; aesthetics and politics; political belonging. 


\section{Introdução}

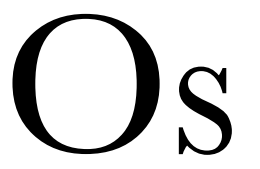

desafios colocados pelo acirramento de

discursos conservadores e reacionários na política brasileira têm exigido esforços de pesquisadores e pesquisadoras. Este texto intenta contribuir com esta produção recente salientando aspectos daquilo que se pode caracterizar como elementos estéticos na produção do vínculo político no espaço público dentro do bolsonarismo ${ }^{1}$. O objetivo é pensar com base em imagens recentes de eventos de apoio ao mandato de Bolsonaro e visibilizar o que nestas formas de presença é utilizado de modo a instaurar vínculos e fronteiras com outros grupos a partir de formas estéticas ${ }^{2}$. Conforme argumento, trata-se de uma produção simultânea nestas manifestações: enquanto este grupo se afirma segundo uma apresentação estética e política, ele também produz um excedente por exclusão, um antigrupo que é constatado como tal na medida em que é desidentificado com o repertório que representa o primeiro grupo.

Ocupada com as formas de produzir assembleias e comuns por meio de materialidades na forma da ação em conjunto, Butler (2019) se volta ao exame das formas de aparição no espaço político. Como o caso de que trato é o de produção de grandes grupos por meio de ajuntamentos que também devem ser compreendidos na chave da relacionalidade que suas interpelações produzem na cena pública, considero estas observações relevantes. Especialmente porque os exemplos evocados por Butler estão envolvidos em lutas progressistas (como a luta de minorias de gênero e sexualidade e de locais como a Síria e a Palestina). O que os "corpos em aliança" da extrema direita produzem em suas ações conjuntas no espaço

\footnotetext{
${ }^{1}$ Adotando a perspectiva de Pinheiro-Machado e Freixo (2019), o bolsonarismo pode ser entendido como um fenômeno político que transcende a própria figura de Jair Bolsonaro e que se caracteriza por uma visão de mundo ultraconservadora, que prega o retorno aos "valores tradicionais" e assume uma retórica nacionalista e "patriótica", sendo profundamente crítica a tudo aquilo que esteja minimamente identificado com a esquerda e o progressismo".

${ }^{2}$ Esta dimensão do laço social e suas dimensões estéticas/materiais é um tema abordado desde distintos olhares na teoria social. Não tenho espaço para pormenorizar este argumento, mas enfatizo que esta é uma recorrente preocupação teórica, com diferentes rendimentos, seja na formulação das "comunidades imaginadas", de Anderson (2008) até as "formas sensoriais" de Meyer (2019), passando pelo aporte da teoria atorrede (Latour 2012).
} 
público e que novas posições de aparição a sua performatividade interpela? Creio que o exame de alguns casos dentro do repertório do bolsonarismo pode dar visibilidade a certos mecanismos de sua lógica interna.

\section{"Brasil acima de tudo, Deus acima de todos"}

$\mathrm{O}$ uso de uma retórica simultaneamente nacionalista e religiosa está presente desde a campanha eleitoral de Jair Bolsonaro. Combinada com a menção à passagem bíblica (8:3, "Conhecereis a verdade e a verdade vos libertará"), a frase "Deus acima de tudo, Brasil acima de todos" é acionada recorrentemente, bem como símbolos nacionais como a bandeira brasileira e, principalmente, suas cores: verde e amarelo $^{3}$.

$\mathrm{O}$ verde e o amarelo, que estavam presentes nas ruas em ações políticas de recorte de direita pelo menos desde as manifestações de 2013 (como no caso do MBL - Movimento Brasil Livre), parecem receber no contexto do bolsonarismo uma ação de identificação de adesão ao seu governo. Estes elementos (as cores e a própria bandeira nacional) partem de uma ação que vai do geral (o nacional) ao específico (o governo Bolsonaro e o apoio a este) numa operação que veicula um sentido de maioria. De fato, o atual presidente já proferiu falas que operam pela chave da maioria - e uma maioria que tem em si o fundamento da ação política ${ }^{4}$.

\footnotetext{
${ }^{3}$ Uma iniciativa no campo das políticas do governo e que aciona este repertório de símbolos gerando novos significados pode ser vista, por exemplo, no caso da "Carteira de Trabalho Verde e Amarela", proposta pelo Ministério da Economia que flexibilizava o pagamento de direitos trabalhistas e contribuições. Poder-se-ia citar também políticas como o "Renda Brasil", que intenta reformar o programa Bolsa Família, associado a mandatos anteriores do Partido dos Trabalhadores (PT).

${ }^{4}$ Cf. "Frases de Bolsonaro, o candidato que desprezas as minorias", IstoÉ. Disponível em: https://istoe.com.br/frases-de-bolsonaro-o-candidatoque-despreza-as-minorias/. Acesso em julho de 2020.
} 


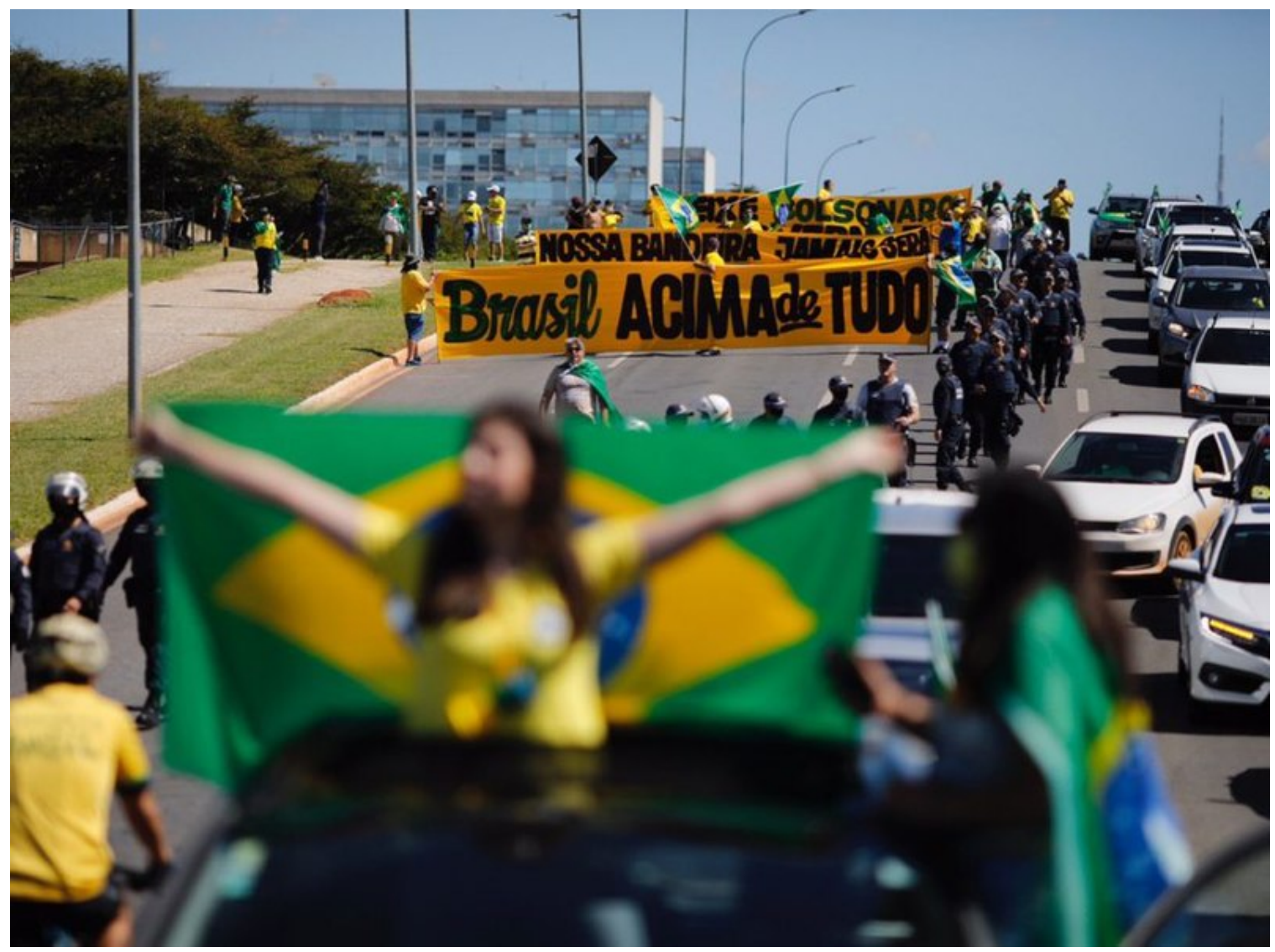

Imagem 1 - Carreata de apoio à presidência e contra as políticas de isolamento dos governos estaduais, em maio de 2020. Crédito: Rodrik Martins.

Tenho identificado nas redes sociais iniciativas de resistir ao que tem sido percebido como o "sequestro" dos símbolos nacionais. Ainda em maio de 2020, começou uma campanha nas redes sociais de utilização da bandeira nacional por pessoas que não se identificam com o governo. "\#Devolvam nossa bandeira" foi idealizada pelo criador de conteúdo digital Felipe Neto e ganhou adesão de políticos do PCdoB, da Rede, do PSol e do PT, bem como da União Nacional dos Estudantes ${ }^{5}$.

\footnotetext{
5 Cf. "Vamos recuperar nossas cores, diz Felipe Neto sobre uso da bandeira nacional", Hora do Povo. Disponível em: https://horadopovo.com.br/vamos-recuperar-nossas-cores-diz-felipeneto-sobre-uso-da-bandeira-do-brasil/. Consulta em julho de 2020.
} 
Vamos recuperar as cores do nosso país. Vamos voltar a ter orgulho do verde, amarelo, azul e branco.

Convido a todos a assumirem a bandeira do Brasil em seus nomes e suas vidas, nessa campanha nacional, apartidária.

\section{$\theta \theta \theta \theta \theta \theta \theta$}

\section{\#DevolvamNossaBandeira}

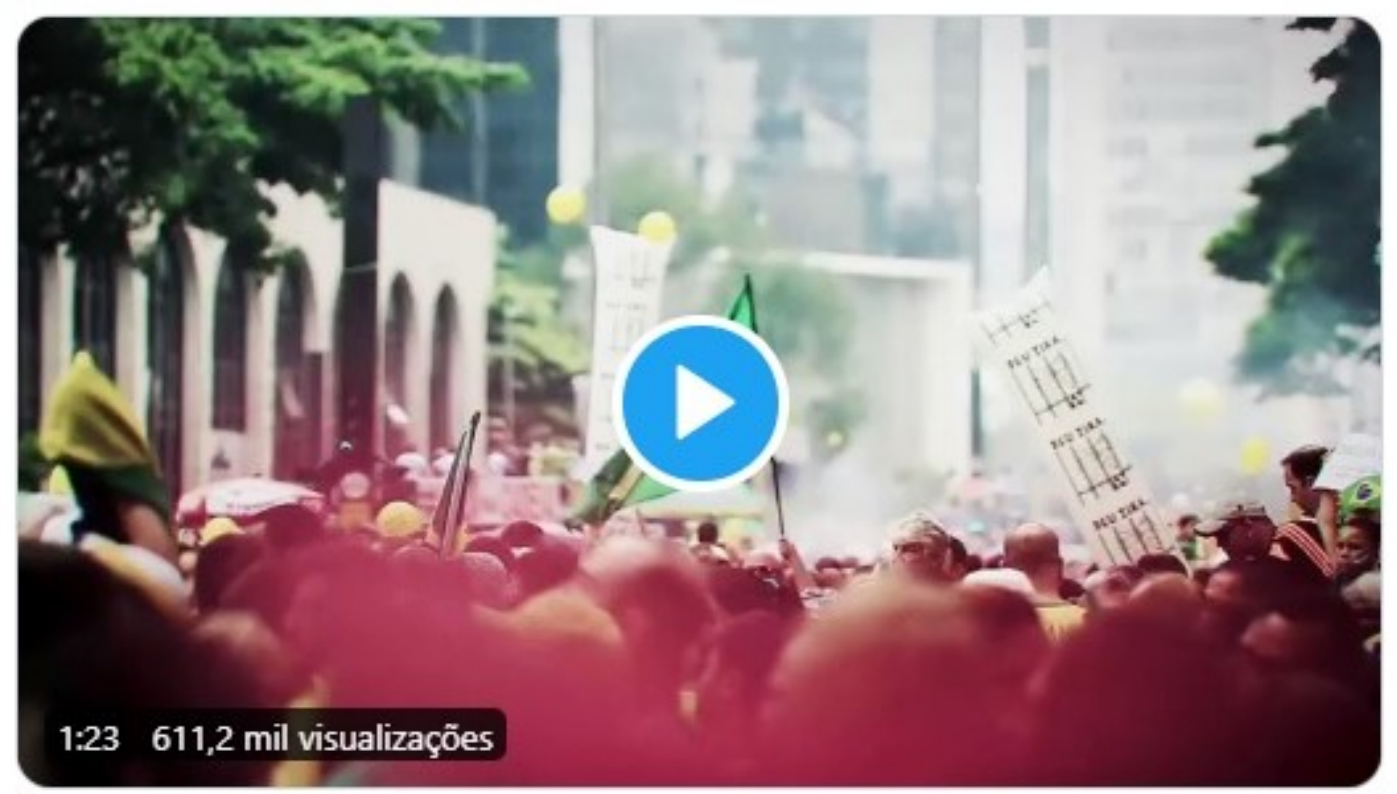

Imagem 2: Campanha "Devolvam a nossa bandeira" nas redes sociais"

Ao lado da bandeira brasileira, a campanha estimulava também o uso da bandeira em preto nas redes sociais junto ao nome do usuário, em razão do "luto pela realidade que estamos vivendo nesse momento, por todas as mortes causadas pela pandemia [de coronavírus]". Entre adesões e rejeições da campanha (para alguns, pensar em reivindicar os símbolos nacionais "de volta" seria impossível, tendo em vista o êxito do bolsonarismo em instrumentalizá-los), tal processo põe em relevo

6 Fonte: Reprodução Twitter Brasil. Disponível em: https://twitter.com/felipeneto/status/1278403975126102023. Consulta em agosto de 2020. 
algumas das consequências do uso do verde e amarelo e a bandeira nacional como repertório político pelos apoiadores do presidente: trata-se de um nacionalismo que opera pela exclusão e que, se identificando como uma "maioria" - patriota e cristã produz uma desidentificação das populações que não são enquadradas nesta narrativa junto à nação. A nação do bolsonarismo teria, assim, indivíduos que são "internos" ao país, mas que são "externos" do ponto de vista do pertencimento simbólico - posto que não participam deste vínculo sintetizado na expressão "Brasil acima de tudo, Deus acima de todos". O fato da campanha "Devolvam nossa bandeira" fazer uso desse repertório nacionalista aponta também para uma tentativa de utilizar a estratégia do bolsonarismo na (re)criação de vínculos e comunidades por meio de elementos estéticos. É comum, aliás, que apoiadores do governo Bolsonaro utilizem junto aos nomes em redes sociais as bandeiras de três países: a bandeira brasileira, a bandeira estadunidense e a bandeira israelense. Esta manifestação não ocorre apenas nas redes sociais, mas encontra espaço nas manifestações de ações públicas de setores bolsonaristas, como veremos no item a seguir.

\section{Israel + Brasil}

A presença da bandeira de Israel na cena pública não é um elemento novo no país. Ela já se fez presente, por exemplo, em eventos de corte religioso evangélico, como a Marcha para Jesus ${ }^{7}$. Nesta configuração dentro de manifestações de grupos bolsonaristas, contudo, a bandeira de Israel aparece associada à brasileira junto a outro símbolo: a bandeira dos Estados Unidos.

Preocupados com a forma como esta visibilização de representações de Israel e do judaísmo tem se dado, para além das formas de apresentação que os próprios judeus possam controlar, certos membros e entidades da comunidade judaica se manifestaram nos dias seguintes a estes eventos de maneira contrária ao uso da bandeira israelense por grupos bolsonaristas. Já no dia 04 de maio, o presidente da Confederação Israelita do Brasil (Conib), Fernando Lottenberg, manifestou em nota preocupação de que "o símbolo de Israel seja confundido com

\footnotetext{
${ }^{7}$ Um registro pode ser visto na matéria sobre a Marcha para Jesus de São Paulo (a maior do país) de 2019, no blog Saída pela direita, disponível em: https://saidapeladireita.blogfolha.uol.com.br/2019/06/20/marcha-parajesus-tem-oracao-para-policiais-e-exibe-simbolos-da-direita/. Consulta em julho de 2020.
} 
alguma corrente político-ideológica ou com intenções antidemocráticas" ${ }^{\prime \prime}$.

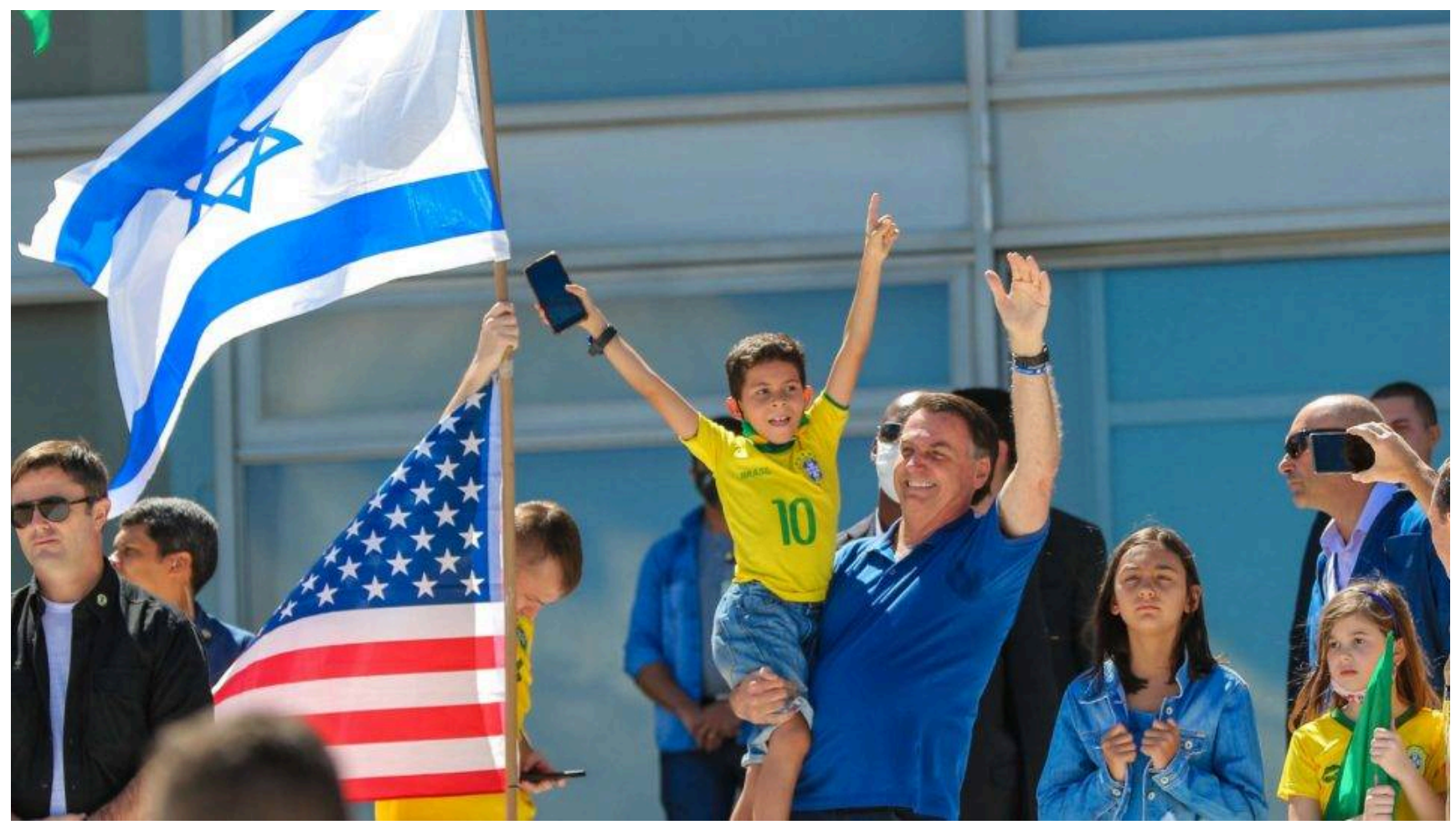

Imagem 3: Manifestação a favor de Bolsonaro do dia 03 de maio de 2020. Fonte: Gazeta do Povo, 4/5/20209, fotografia de Wagner Pires/Futura Press.

Ainda em maio, o grupo Fudeus pela democracia junto ao Instituto Brasil-Israel (IBI) realizou uma live nas redes sociais a fim de discutir estas questões, em evento denominado "Governo Bolsonaro e o judeu imaginário", diagnosticavam o problema: há uma insistência dos bolsonaristas em apresentar ao público uma ideia de que os judeus seriam apoiadores do governo Bolsonaro, apagando a pluralidade de posições políticas dentro dos grupos judaicos. A produção deste

${ }^{8}$ Cf. "Confederação Israelita lamenta bandeiras de Israel em ato antidemocrático", Uol. Disponível em: https://noticias.uol.com.br/colunas/chicoalves/2020/05/04/confederacao-israelita-lamenta-bandeiras-de-israelem-ato-antidemocratico.htm. Consulta em julho de 2020.

${ }^{9}$ Disponível em: https://www.gazetadopovo.com.br/republica/bandeirasisrael-eua-manifestacoes-pro-bolsonaro/, consulta em julho de 2020. 10

Disponível

em: https://www.facebook.com/watch/live/?v $=3126074654081493 \& \mathrm{ref}=\mathrm{w}$ atch_permalink. Consulta em 22 de julho de 2020. 
"judeu imaginário" partidário do bolsonarismo levaria a consequências bastante imprevistas, como uma grande visibilidade do judaísmo enquanto grupos religiosos mais afinados com Bolsonaro como os evangélicos se secundarizariam nestas cenas públicas. Um dos painelistas do evento salientou como esta produção de imaginário teria penetração na percepção pública dos fatos políticos, turvando a realidade como no fato do ex-ministro Abraham Weintraub ser costumeiramente identificado como judeu (mesmo não sendo) enquanto um jornalista crítico ao governo como Glenn Greenwald não ser identificado como judeu (embora o seja).

Outro panelista colocava a questão nos seguintes termos: existiria no bolsonarismo uma ambivalência, com filosemitismo (com a ideia de Israel convertida à de um Ocidente militarizado) convivendo com o discurso nazista (como no discurso que culminou com a demissão de Roberto Alvim, da Secretaria Especial da Cultura). Para certos grupos judaicos progressistas, portanto, o "sequestro" de referências - religiosas, históricas e culturais - de elementos israelenses e judaicos aconteceu de maneira próxima à que ocorrera com símbolos nacionais brasileiros. Esta forma de apropriação, com efeito, não é a simples transposição ou um acúmulo desordenado de referências, mas um rearranjo que faz estes elementos funcionarem segundo outra lógica, a do bolsonarismo, com as quais os elementos originalmente não poderiam coincidir sem certo curto-circuito ideológico. Enfatizo que esta forma de referência a Israel (como espaço) não é de todo novidade no que se refere ao bolsonarismo: o próprio Bolsonaro foi batizado nas águas do Rio Jordão no ano de 2016, pelas mãos do religiosopolítico evangélico Pastor Everaldo ${ }^{11}$. Ainda em 2016, Carlos e Eduardo Bolsonaro foram fotografados em visita a Israel utilizando as camisetas das Forças de Defesa de Israel e do Mossad, serviço secreto israelense ${ }^{12}$. Assim, as formas de organizar as referências relacionadas ao militarismo do Estado

11 Cf. "Enquanto votação do impeachment acontecia, Bolsonaro era batizado em Israel", Extra. Disponível em: https://extra.globo.com/noticias/brasil/enquanto-votacao-doimpeachment-acontecia-bolsonaro-era-batizado-em-israel19287802.html. Consulta em julho de 2020.

12 Cf. "ONG internacional relembra foto de filhos de Bolsonaro com camisetas do Mossad e das forças de defesa de Isarael", Época. Disponível em: https://epoca.globo.com/expresso/ong-internacional-relembrafoto-de-filhos-de-bolsonaro-com-camisetas-do-mossad-das-forcas-dedefesa-de-israel-23212174. Consulta em julho de 2020. 
israelense e ao significado religioso-político deste enquanto lugar simbólico potente mostram uma relação duradoura.

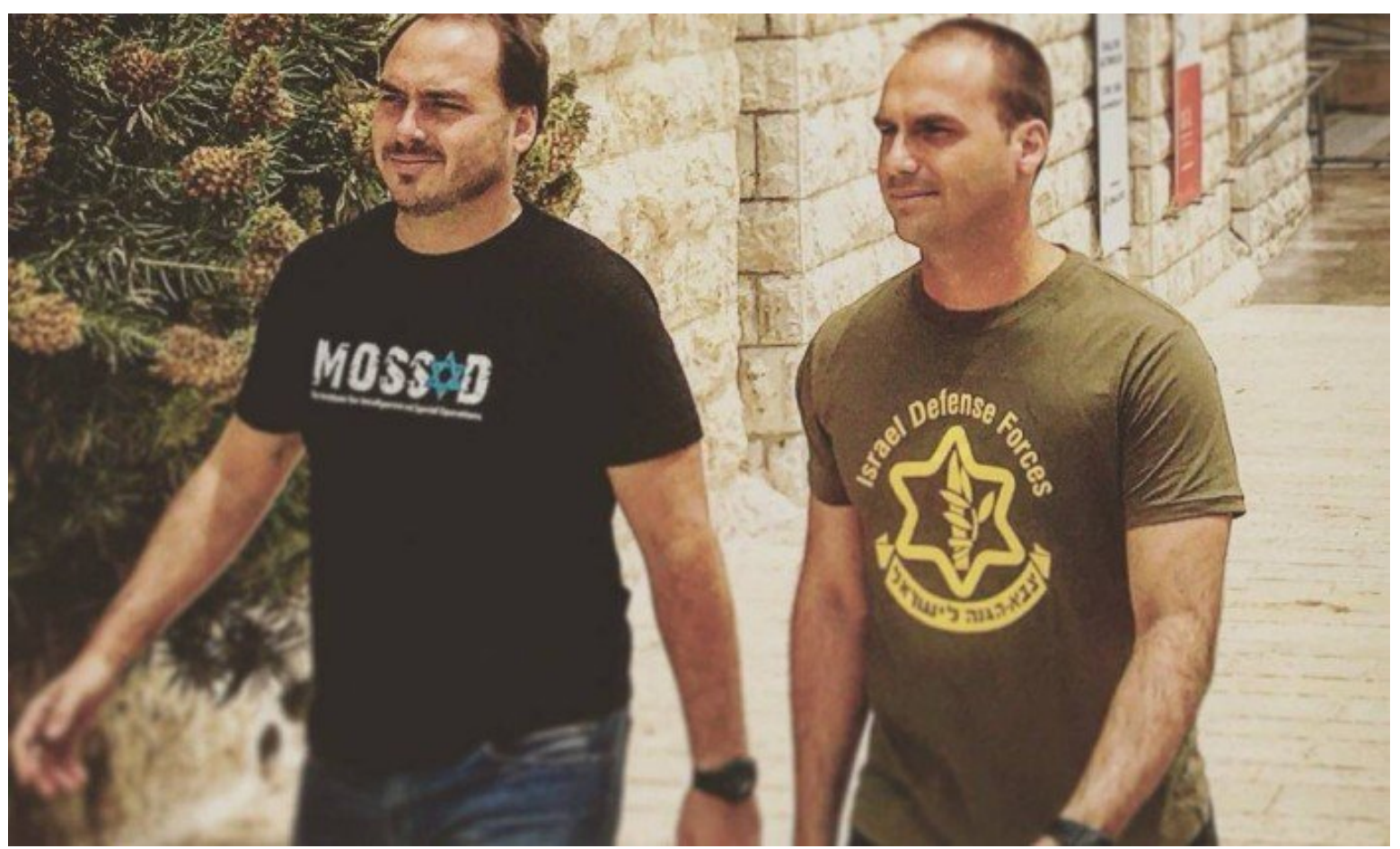

Imagem 4: Carlos e Eduardo Bolsonaro utilizando roupas de exército israelense. Fonte: Reprodução do Instagram de Eduardo Bolsonaro pelo UOL, em 07/11/201813.

\section{Da força projetiva das imagens}

Ocorreram muitas manifestações de apoiadores em cenas públicas em mais de 16 meses de governo Bolsonaro. Escolhi algumas delas a fim de discutir o tema da articulação entre estética e política de modo a perceber como esta convergência pode ser um bom índice para pensarmos a produção de laços sociais e simbólicos no bolsonarismo. Spivak e Butler (2018) endereçam questões interessantes sobre o tema do pertencimento e do binômio cidadania/exclusão aludindo, também, a questões que estão politizadas como a linguagem e a performance. O caso citado pelas autoras da ocupação de espaços nos Estados Unidos por imigrantes hispânicos nãolegalizados cantando o hino estadunidense em espanhol é

13 Disponível em: https://noticias.uol.com.br/internacional/ultimasnoticias/2018/11/07/post-antigo-de-filhos-de-bolsonaro-com-

camisetas-de-forcas-israelenses-gera-polemica-em-israel.htm. Consulta em agosto de 2020. 
tratado por Spivak e Butler como uma "contradição performativa", uma vez que, por uma questão legal, o hino só poderia ser cantado em inglês. $\mathrm{O}$ que estas populações estariam colocando diante do Estado, assim, seria o desafio de por em circulação formas não autorizadas de reiterar a Nação (2018: 58). No caso das "multidões bolsonaristas" munidas de símbolos nacionais, enquanto se proclamam maiorias com o poder de suprimir minorias, mesmo que estes grupos estejam no interior desta mesma nação, quais as consequências desse tipo de contradição performativa?

Penso, reunindo as imagens trazidas até este momento, naquilo que elas interpelam ao real e o quanto podemos ver nestas manifestações formas mitopoéticas (Spivak e Butler 2018) de veiculação de uma mensagem política. Como sugerem as autoras, ao nos desfazermos da oposição do performativo em relação ao político e do mito à política, podemos estar atentos a como certos projetos se colocam no espaço público agenciando formas de pertencimento não previstas e como a curta distância entre aquilo que projetam (imagens, elementos estéticos) e o tipo de ação que intentam no mundo podem agir discursivamente e materialmente na realidade, trazendo diversas consequências para o tema da cidadania.

\section{Referências bibliográficas:}

ANDERSON, Benedict. 2008. Comunidades imaginadas: reflexões sobre a origem e a difusão do nacionalismo. São Paulo: Companhia das Letras.

BUTLER, Judith. 2019. Corpos em aliança e a política das ruas. Notas para uma teoria performativa de assembleia. Rio de Janeiro: Civilização Brasileira.

LATOUR, Bruno. 2012. Reagregando o social: uma introdução à teoria ator-rede. Salvador: Edufba; Bauru: Edusc.

MEYER, Birgit. 2019. "De comunidades imaginadas a formações estéticas: mediações religiosas, formas sensoriais e estilos de vínculo". In: Emerson Giumbelli; João RicklI, João e Rodrigo Toniol (Orgs). Como as coisas importam: uma abordagem material da religião. Textos de Birgit Meyer. Porto Alegre: Editora da UFRGS. p. 43-80.

PINHEIRO-MACHADO, Rosana; FREIXO, Adriano de (Orgs.). 2019. Brasil em transe: Bolsonarismo, nova direita e desdemocratização. Rio de Janeiro: Oficina Raquel. 
SPIVAK, Gayatri Chakravorty; BUTLER; Judith. 2018. Quem canta o Estado-Nação? Lingua, política, pertencimento. Brasília: Editora UnB.

Enviado: 5 de agosto de 2020 Aceito: 11 de novembro de 2020 